DECEMBER 2020

Resilience

\section{in 2020}

Field research on how nonprofits are faring amid crisis and disruption.
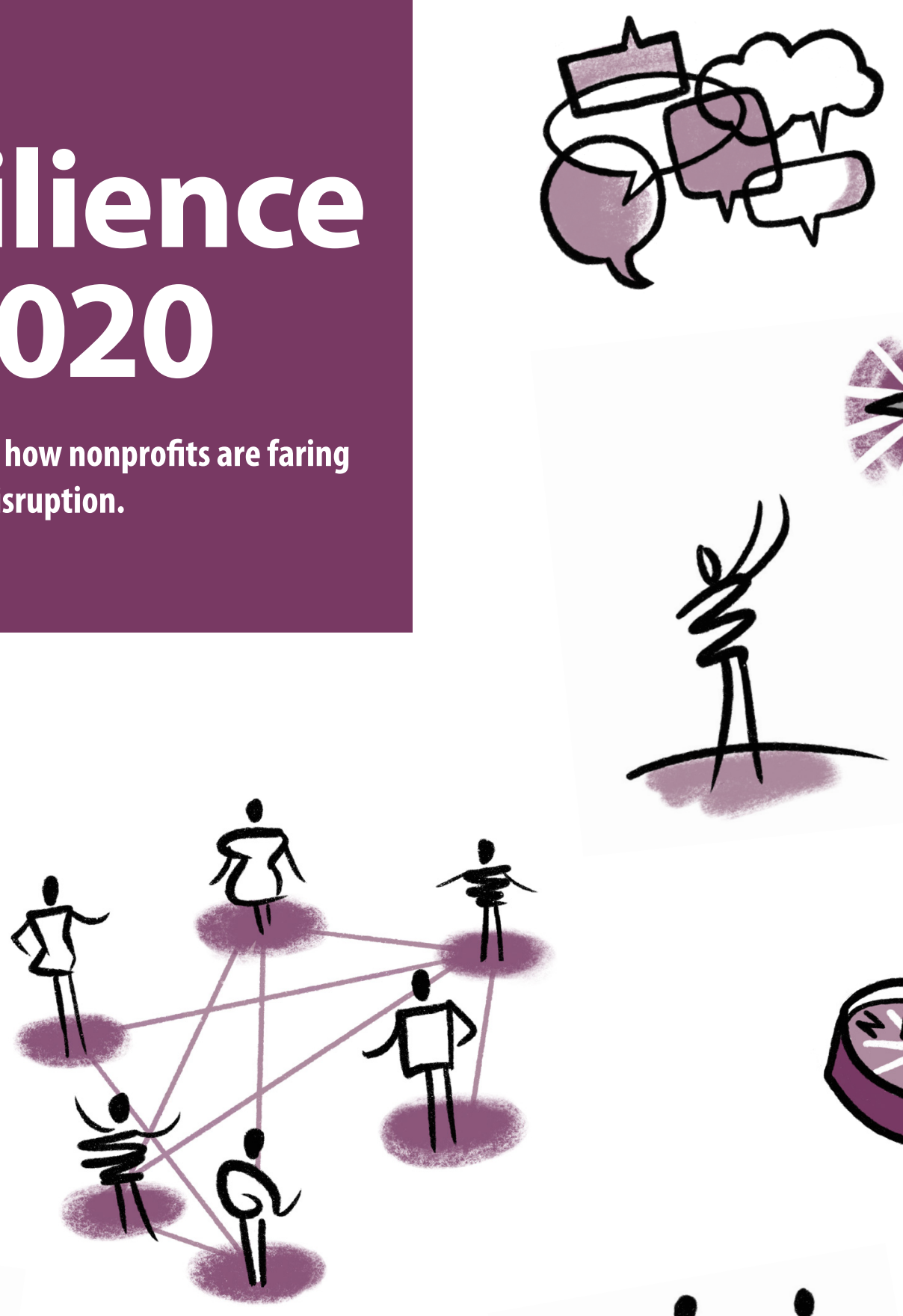
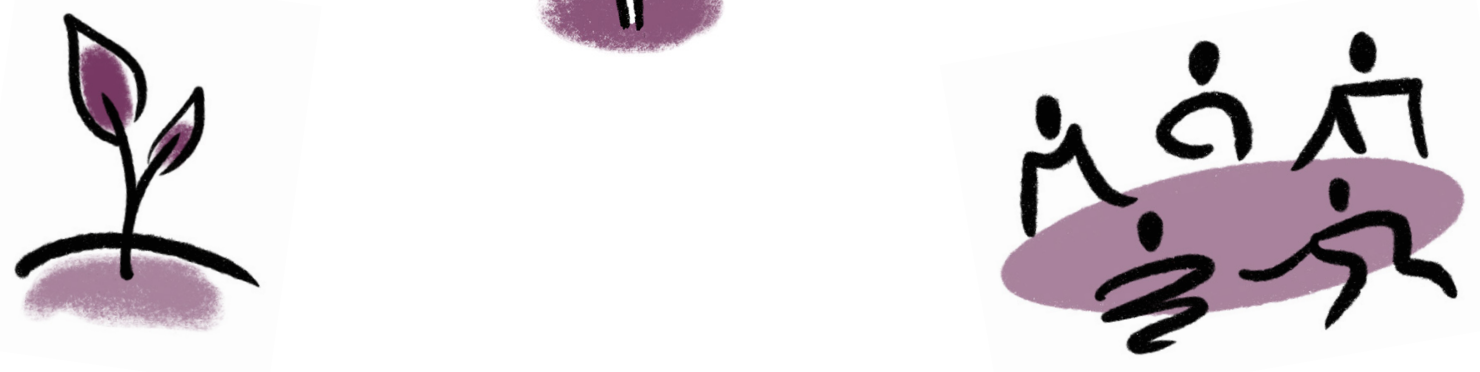

Funded by: 


\section{Table of Contents}

3 Introduction

5 How the crises of $\mathbf{2 0 2 0}$ have impacted nonprofits

7 Momentum for change: Elevating equity, embracing digital

9 Seven characteristics of resilient organizations

18 How funders can contribute to nonprofit resilience

$22 \quad$ Looking toward a better future

23 Stories of nonprofit resilience in $\mathbf{2 0 2 0}$

24 Dimensions Dance Theater: Connected to community

25 HOPE Services Hawai'i, Inc.: Leveraging networks and adapting quickly for disaster response

27 National Immigration Law Center: Swift adaptation guided by strategic clarity

29 NatureBridge: Preparing to reemerge stronger, with equity at the center

31 Partnership for Public Service: Ready to pursue unanticipated opportunity

33 United Philanthropy Forum: Reinvented for these times

35 Acknowledgments, including interview list

37 Endnotes

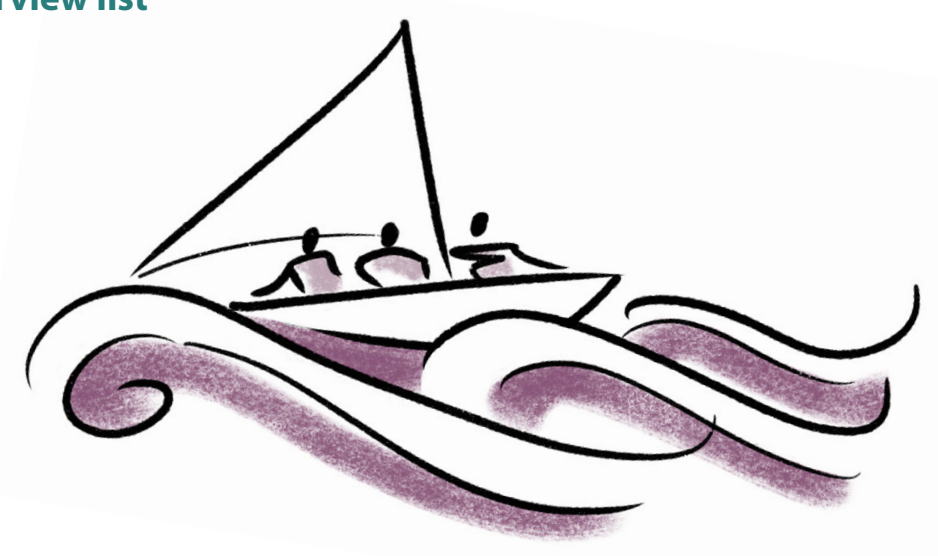




\title{
Introduction
}

\author{
In fall 2018, the S. D. Bechtel, Jr. Foundation, along with fellow funders and the \\ authors of this report, set out to study what it takes for nonprofits to survive and \\ even thrive amid disruption, and to better understand how grantmakers can help \\ grow this resilience. We defined "resilience" as a nonprofit's ability to respond \\ effectively to change and adapt successfully to new and unforeseen circumstances \\ while staying true to mission.
}

Over the next 15 months, we interviewed nearly 60 nonprofit leaders who had bounced back from a range of disruptions: difficult leadership transitions, shifts in funding priorities, policy wins and losses, hurricanes, wildfires, cyberattacks, and more. We also spoke with about 30 funders committed to supporting nonprofit resilience. Throughout, we listened for how nonprofits were responding and adapting to major change and turbulence.

Ultimately, seven characteristics emerged as critical to organizational resilience: purpose driven, clear eyed, future oriented, open, empowered, committed to self-renewal, and connected. We presented these characteristics in our resulting report, Resilience at Work.

\section{RESILIENCE SERIES}

This study builds on and complements the Resilience at Work research published earlier in 2020. It also complements the recently updated Resiliency Guide, which describes the seven characteristics of resilient nonprofits and prompts discussion and actions that can fuel resilience.

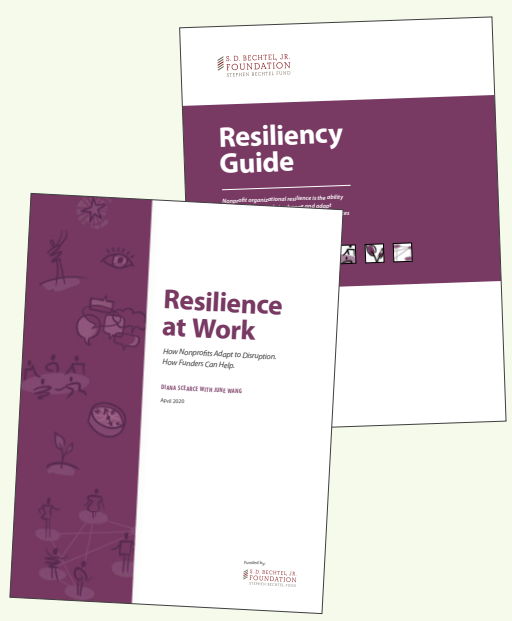




\section{WAVES OF CHANGE, UPDATED RESEARCH}

None of the stressors profiled in the original study reached the magnitude of the multiple and interconnected crises that have defined 2020 - the pandemic, the uprising for Black lives and racial justice, the economic downturn, the crescendo of natural disasters. We wanted to know: What does it take for nonprofits to be resilient in the face of the profound and far-reaching change and uncertainty that no organization has been immune from this year? Can nonprofits bounce back better equipped to weather future crises?

To find out, the S. D. Bechtel, Jr. Foundation commissioned this update. Resilience in 2020 explores what nonprofit experiences over the past several months can tell us about resilience. We went back to a subset of the exemplars featured in the original study to find out what they've been experiencing and what is contributing to their resilience in these turbulent times. In total, we interviewed 22 leaders at 19 nonprofits and intermediaries in September and October $2020{ }^{1}$

\section{Here's what we learned:}

-While 2020 has been excruciating for most nonprofits, organizations that had already put in the work to build resilience have been nimble, intentional, and creative in rising to meet the needs of the moment.

> Nonprofits are reimagining themselves for our changed and changing world. They are squarely centering equity and operating with growing fluency in a digital age. In a sense, the twin pandemics of COVID-19 and racism have accelerated trends already underway and compelled nonprofits to lean into truths increasingly visible to all.

> The seven characteristics of resilient nonprofits identified in the original Resilience at Work study have largely held true in the face of the stressors and shocks of 2020. Being purpose driven, agile, committed to self-renewal, and connected stood out as particularly critical in these times. We reframed the third characteristic from "future oriented" to "agile," to more appropriately name the nimbleness needed amid such extreme conditions of uncertainty. Nonprofits are remaining agile by learning from what is and isn't working, rehearsing the future, and then navigating the present with a readiness to respond to disruption.

- Funders are responding and adapting by embracing more trust-based, relationship-centric approaches to their work, a shift that is well aligned with funder recommendations highlighted in the original study. The question is: Will the change stick? 


\section{How the crises of 2020 have impacted nonprofits}

Throughout the spring and summer of 2020, the mindset for many nonprofits and funders was "let's get through this, and then we can go back to normal." As we write this in late fall, the notion that the current turbulence and uncertainty will end anytime soon has begun to fade away. Instead, many accept that this disequilibrium will last for the foreseeable future. It's reasonable to believe that more stability will come at some point - but there will be no return to "normal" as we once knew it.

Nonprofits, and social changemakers of all stripes, have a choice: cling to old ways of being, or let go and reimagine themselves for a new reality. Novelist Arundhati Roy's words are a poignant reminder: "[The pandemic] is a portal, a gateway between one world and the next. We can choose to walk through it, dragging the carcasses of our prejudice and hatred, our avarice, our data banks and dead ideas, our dead rivers and smoky skies behind us. Or we can walk through lightly, with little luggage, ready to imagine another world. And ready to fight for it."2

The resilient nonprofits we spoke with are ready to imagine another world and ready to fight for it. They're moving beyond the original emergency of COVID-19 last spring and learning to live with the virus and remote work. They've internalized the uprising in the aftermath of the murders of George Floyd and Breonna Taylor, deepening their actions and commitments to racial justice and equity.

They're bracing themselves for spikes in COVID-19 this winter,

The resilient nonprofits we spoke with are ready to imagine another world and ready to fight for it. continued uncertainty around the state of our democracy, a volatile economy, and anticipated funding challenges in 2021. And, throughout, they're demonstrating resilience. ${ }^{3}$

This "settling in" effect does not diminish the brutal reality of 2020 for these nonprofits and the communities they serve.

The impact of the pandemic has been "horrific" and an "Armageddon scenario," in the words of one leader. An estimated 7\% of all U.S. nonprofits will close shop because of the pandemic and one million nonprofit jobs have already been lost. ${ }^{4}$ 
Early research by Independent Sector suggests that small organizations may be hardest hit. Moreover, research has shown that organizations led by people of color (POC), and Black people in particular, have smaller budgets on average, suggesting that the negative financial impacts of COVID-19 may disproportionately affect POC-led organizations. 5,

When the pandemic took hold and many nonprofits had to suspend programming and/or respond to new needs, having unrestricted cash on hand was critical to making it through the early crisis. Leaders spoke of how important it was to have flexible funds to support staff in the transition to remote work, to cover lost revenue and staff

Having unrestricted cash on hand was critical to making it through the early crisis resulting from the pandemic. time while repositioning to deliver on mission under dramatic and dynamic conditions, and to invest in new activities that address urgent needs.

Nonprofits were able to access flexible dollars by cutting costs, by funders loosening restrictions on grants, and through the

Paycheck Protection Program (PPP). For many, the PPP provided an essential lifeline in the early days of COVID-19, allowing them to hold onto staff as they explored longer-term plans. The Partnership for Public Service's President and CEO Max Stier characterized the PPP as "a lifesaver... . It balanced our books and gave us a runway to figure out what's next." Some who were granted PPP funds didn't end up using them. But simply knowing that they had the cushion during such an unstable period helped these organizations'leaders move forward with greater confidence. 


\title{
Momentum for change
}

\author{
COVID-19 and the uprising for Black lives have accelerated fundamental shifts \\ already underway toward nonprofits elevating equity and embracing digital \\ practices inside their organizations and in the world. Some organizations are being \\ jolted out of old ways of being and working. Others have long been living these \\ realities and are now watching partners and other players in their systems catch up.
}

\section{Elevating equity}

The murders of George Floyd and Breonna Taylor, continued violence against Black people, and the movement for racial equity have compelled nonprofits to respond and adapt to different degrees, depending on how much they needed to wake up to the realities of generational racial trauma and structures of oppression.

For the Black-led and Black-serving organizations we spoke with, addressing this current moment when centuries-old racial inequity has been laid bare has largely meant pressing on and continuing to support Black communities as they have from the beginning. Some have seen increased support in the form of more funding and more volunteers, but there is uncertainty about whether these new commitments will continue and for how long. There is also hope, though, that addressing structural racism will remain a priority. As Deborah Vaughan, executive director of Dimensions Dance Theater, reflected, "For many of us people of color, it feels like what our ancestors went through with civil rights. You're seeing history being repeated ... I just hope that this is a time of reckoning for our nation - for us to not only ask but demand change. We can clearly see what's happening to the earth, economy, education, our children. We need to revamp."

Organizations that were already explicitly working to advance equity, and racial equity in particular, are tapping into new and strategically aligned opportunities to accelerate these efforts. For example, when the United Philanthropy Forum relaunched in 2017, advancing racial equity was central to their vision of "a courageous philanthropic sector." In the summer of 2020, the Bill and Melinda Gates Foundation (BMGF) wanted to address the fact that the populations most affected by the pandemic were those that have historically been marginalized and often don't have adequate capacity. The Forum was a natural partner for BMGF to select to run its $\$ 9.1$ million Momentum Fund; the Fund supports capacity building through intermediaries that are granting COVID-19 relief and recovery funds to organizations serving communities most impacted by the pandemic.

For other nonprofits we spoke with, especially those that are white-led, this has been a moment of awakening to centuries of racial injustice. These leaders are seeing the opportunity and imperative to help usher in a more just and equitable future, and spoke of doubling down on internal diversity, equity, and inclusion efforts that were moving at a slower pace prior to the pandemic. They are 
looking inward, working toward inclusive and equitable organizational cultures and operations. Many have cross-staff working groups exploring how issues of equity and inclusion show up in their work. Some are bringing on leaders who are more racially diverse and better reflect the communities served. Several are developing shared language for ongoing dialogue and action to deepen their commitments. This internal-facing work is also helping some of the organizations look outward at what it means to center equity in the difference they are making in the world. Yet, despite the imperative for accountability and action, it can be challenging to advance equity and inclusion efforts when many nonprofits are facing hiring or salary freezes and occupied with the demands of COVID-19 response efforts.

\section{Embracing digital}

The shutdown catapulted many nonprofits into the digital realm, radically altering how they work as teams and opening new pathways to service delivery.

For most organizations, remote work and smaller office footprints will be part of their model going forward. ${ }^{7}$ For organizations with a subset of team members in other geographies, a workplace that is predominantly remote "levels the playing field." Staff at Candid, the social impact data organization recently created from the merger of GuideStar and the Foundation Center, discovered a democratizing effect of working from home. Prior to the pandemic, staff working outside of the largest offices sometimes felt left out of decision-making. Now, according to Executive Vice President Jacob Harold, there's a "sense of equality with everyone working from home."

Others spoke of new possibilities for convening large and geographically distributed groups, inside and outside their organizations, thanks to lower-cost, scalable venues and logistical simplicity. For example, the Partnership for Public Service holds an annual gala for their "Service to America" awardees, typically attended in person by 600 people. In 2020, their awardees were celebrated virtually by over 150,000 people over the course of a week.

A transition to remote work carries tradeoffs. The isolation, loss of community, dips in morale, and communications issues are real. At the same time, for those doing office-based work (as opposed to essential service delivery), it's hard to imagine reverting back to mostly in-person work arrangements, requiring regular commutes and expensive leases, and restricting recruiting to only local talent. Most leaders we spoke with see a hybrid model on the horizon.

The move toward online programming is also accelerating. For many, it will be an important part of the mix going forward. This is particularly true for nonprofits offering training and educational programming. Organizations are now engaging program participants who were once considered reachable only through opening offices in new locations or conducting major expansions. Some nonprofits, like the California Academy of Sciences, which had previously viewed its educational offerings as local and hands-on, are now serving people around the globe. Most organizations we spoke with are unlikely to transition entirely to online programming. They value, for instance, the power of in-person learning experiences, and want to avoid practices that could further exacerbate inequitable access and the digital divide. But a hybrid model seems here to stay. 


\section{Seven characteristics of resilient organizations}

Resilient nonprofits were ready to respond, adapt, and fight for a better future when disruptions hit (again and again) this year. They entered this historically tumultuous time already having cultivated organizational resilience. As they've navigated through the waves of change they have continued to grow their resilience, preparing for the prolonged uncertainty and turbulence that is still to come.

What specifically does it mean for nonprofits to be resilient in 2020? The seven characteristics of resilient organizations identified in our original research hold true:

\section{Purpose driven}

A galvanizing commitment to mission, meaning, and values

Leaders spoke of being guided by purpose and a corresponding clarity of strategic direction, facilitating swift and mission-aligned decision-making amid current crises.

\section{Clear eyed}

Challenges faced head-on while maintaining faith in ultimate success

Resilient organizations are accepting the harsh reality of the compounding crises and prolonged uncertainty, while continuing to see a path through to a better tomorrow.

\section{Agile}

Future-oriented planning and adaptive management practices for navigating an uncertain future

Interviewees stressed the power of nimbleness, flexibility, and the ability to pivot in this time of uncertainty, informed by both learning from the past and looking to the future. (Our original research used the label "future oriented" for this characteristic.) 


\section{Open}

\section{Intentional communication and connection with stakeholders}

Frequent and clear communication with staff, coupled with trusting team relationships, is critical for alignment and morale when working remote - and adapting to rapid change.

\section{Empowered}

\section{Inclusive and equitable organizational cultures that embrace shared leadership}

Cultivating inclusive organizational cultures and empowering staff to lead have heightened relevance when leaders recognize the imperative of centering equity inside their organizations and in their work in the world.

\section{Committed to self-renewal}

\section{Space created for rest and rejuvenation}

In an era of anxiety and compounding stressors on personal and professional lives, attention to the well-being of staff has reached a new level of significance. A commitment to self-renewal is an essential priority if nonprofits are to retain staff and cultivate the caring and compassionate organizations that are so needed today.

\section{Connected}

\section{Supported by personal relationships, institutional links, and community networks}

Nonprofits that are making it through the disruptions of 2020 are not doing so alone. They're connected to and in reciprocal relationships with individuals and groups outside their organizations, including peers, advisors, allies, and communities.

Organizational resilience does not exist in a vacuum. In addition to the seven characteristics, resilient nonprofits are powered by resilient leaders and teams, and embedded in resilient communities. However, the larger systems in which they operate can create significant structural barriers to resilience for communities served as well as nonprofits. In the words of one nonprofit leader, ${ }^{\text {"There needs to }}$ be an analysis of the external trauma imposed by these systems on the populations we serve and our organizations." For funders, this means assessing and investing in the long-term systemic changes critical for moving toward an equitable future (e.g., reimagining criminal justice and economic systems). It also means examining and shifting the system of philanthropy itself (e.g., addressing the inequitable access that Black-led nonprofits have historically had to donor networks). 


\section{Purpose driven}

\section{A galvanizing commitment to mission, meaning, and values}

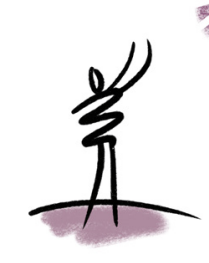

A larger purpose galvanized leaders and their staffs to act with courage and conviction, and a corresponding strategic clarity facilitated swift decision-making that aligned with organizational missions. Leaders reflected on how a deep commitment to mission and purpose pushed them forward, despite sometimes overwhelming and relentless shocks to both their organizations and personal lives. This was especially true for those leaders and staff members with lived experience of the inequity they were working to address; they knew what was at stake for their constituencies and the costs of inaction.

After the shutdown, when the Young Women's Freedom Center (YWFC) transitioned to remote work, more than half of the staff did not have internet access, and needed infrastructure was not in place to support their youth organizers to work virtually. Yet within days they were up and running, advocating for the immediate release of young women and girls from prison. According to Executive Director Jessica Nowlan, while "bureaucrats were trying to meet the needs of staff working at home," the YWFC team was able to meet the basic needs of the community they served. YWFC worked with county officials on a case-by-case basis to get youth released, resulting in all young women out of San Francisco detention. What contributed to YWFC's success? "We are an organization led by systems-impacted people," said Nowlan. "So we have a different understanding of what's at stake."YWFC had also recently developed a clear vision for impact via a ten-year political organizing, culture change, and legislative campaign. "Because of this deep understanding we were able to move into action immediately."

The Young Women's Freedom Center and several other organizations we interviewed benefited from coming into the pandemic with a defined "north star." These nonprofits were able to swiftly

An expressed vision and strategic direction helped leaders discern which activities were critical and which were not. adapt while remaining true to mission. Leaders had clarity about where their respective organizations were headed and, as a result, were able to chart new and timely routes to their north star that made sense in a changed and changing context. For several of these organizations, an expressed vision and strategic direction helped leaders discern which activities were critical and which were not.

This was the case, for example, for the National Immigration Law Center (NILC). Last spring, they decided to step back from work that had become less strategically critical in order to take advantage of the opening to strengthen the narrative around the importance of low-income immigrants as essential workers in this country. After George Floyd's murder in early June, clarity of purpose motivated Tipping Point Community to pause its fundraising for San Francisco Bay Area nonprofits focused on fighting poverty. Instead, Tipping Point directed donors to nonprofits that were active on the frontlines of the racial justice movement. 


\section{Clear eyed}

\section{Challenges faced head-on while maintaining faith in ultimate success}

The brutal reality of the intersecting crises of 2020 has taken time to come into focus. But in fall 2020, the leaders we spoke with were realistic about the long road ahead yet sanguine about their ability to rise to the challenge. "We're trying to be positive and optimistic and confident in what we're doing, while also being honest and transparent, knowing that it isn't all figured out," said Ashley Boren, executive director at Sustainable Conservation. Similarly, Pam lorio, CEO of Big Brothers Big Sisters of America, has been consistent in her message to affiliates across the country that are working to adapt their in-person mentoring model to a socially distanced world: "You'll make it through. Focus on survival, not growth."

Organizations facing huge increases in demand - especially those delivering social services to communities hardest hit by the pandemic - are similarly recognizing the need to be clear eyed about what they can deliver. For example, ECHOS, a Houston-area health and social service

Organizations facing huge increases in demand are recognizing the need to be clear eyed about what they can deliver. organization with a staff of ten, was overwhelmed with 30,000 phone calls in one day asking about financial assistance. They installed a new phone system to handle the huge increase in volume, while also coming to terms with the reality that staff could not continue to service everyone in need. ECHOS made the hard but necessary decision to restrict financial assistance to specific zip codes where the needs seemed greatest and where other organizations were not already offering assistance. This allowed the organization to serve the community fairly while managing its own capacity.

Are nonprofits at risk of being too optimistic, and not clear eyed enough about challenges ahead? Jacob Harold, executive vice president at Candid, voiced a concern that many "keep hoping for the best. We might have more emotional willingness to talk about the hard questions if we started with assumption of the bad scenario. ... Many organizations may not be having the hard conversations." 


\section{Agile}

\section{Future-oriented planning and adaptive management practices for navigating an uncertain future}

The uncertainty of these times is greater than many people have experienced in their lifetimes. Leaders need to simultaneously manage a whirlwind of changes in the present while looking far enough into the future to imagine a better tomorrow.

In the near term, nonprofits are operating with planning horizons of weeks or months rather than years. Agility and nimbleness are prized. Several leaders noted the difficulty of looking very far into the future when the uncertainty is so great. They're embracing adaptive management: learning from recent efforts, applying that learning to upcoming decisions, and moving forward in an incremental and adaptive manner. Health Connected, Nonprofit leaders are asking: a nonprofit that brings sexual health education to schools What will it take to balance the need for responsiveness with intentionality? across California, is investing just enough time and effort in adapting their services to be ready to act if needed, or to pivot again in response to shifting status of the California school districts where Health Connected works. Key to this approach has been engaging the staff team in periodic reflection about what has and has not been working and then using that learning to inform upcoming decisions. As Executive Director Abi Karlin-Resnick described, "[lt feels like] we're driving on a windy, foggy road. We only have one headlight. There is a cliff on one side, and a steep hill on the other. We have to keep going, but only at about five miles an hour so we can swerve if needed."

What will it take to balance the need for responsiveness with intentionality? As United Philanthropy Forum's President and CEO Dave Biemesderfer put it, "How do we have enough direction to guide us while still holding onto our nimbleness?" For some, scenario planning is offering the needed direction. Not surprisingly, several of the leaders mentioned their use of financial scenarios to help them chart a solvent path through different operating conditions. Some organizations were using scenario planning to rehearse possible outcomes and related actions coming out of the election. In addition to looking at the range of election-related uncertainties, the ACLU also considered what was relatively certain and developed a "Systemic Equality" plan for post-election action regardless of election outcomes. 


\section{Open}

\section{Intentional communication and connection with stakeholders}

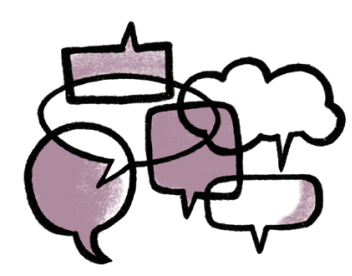

Leaders stressed the importance of open and intentional communication, especially with staff now working remote. Many spoke of an intense period last spring that required near constant all-staff communications to keep people abreast of rapid changes and to check in on one another's wellbeing. This period of constant communication has passed. However, the need to invest in open and ongoing communication remains for many teams working at a distance and without the benefit of hallway encounters or the ease of building trusting relationships in person.

It can be hard for leaders to take the pulse of their organizations when staff are spread apart. For the California Academy of Sciences, open communication was critical in summer 2020 when they restructured the organization in order to stay afloat and continue their scientific research. As a museum and research institute, more than $50 \%$ of their revenue has traditionally been earned, and this revenue stream was reduced to nearly zero when a local shelter-in-place order was issued in

\section{Leaders stressed the} importance of building the trusting relationships that serve as the foundation for openness. the spring. Restructuring, including laying off and furloughing employees, was essential if the Academy were to make it through this period. The restructure raised questions of equity and future job security for some staff. Weekly meetings with ample time for interaction gave space for staff to raise pointed questions and for leaders to help everyone understand shifting priorities and decision-making rationale. "As management and

as leaders we have to make sure we are communicating transparently and frequently, that the values and beliefs are really clear to everybody, and that what we say we're doing is what we're doing," said Melissa Felder, the Academy's chief revenue and marketing officer.

In addition to clear and consistent communication, leaders stressed the importance of building the trusting relationships that serve as the foundation for openness. As Pamela Sergio, director of human resources and administration at Sustainable Conservation, said, "With the shock of shelter-in-place we wanted to avoid relationships slipping into the transactional. ... The most important thing was to recognize that people were going to need that human connection." Interviewees spoke of managers connecting with team members for regular one-on-one conversations, colleagues going on walks (at a distance), and teams placing a premium on having fun together with Zoom happy hours, baby showers, and even charades. "Humor is getting us through," said ECHOS Executive Director Cathy Moore. "We've got to find ways to laugh. If we didn't laugh, we'd cry every day."

It can be tough to maintain relationships and even more difficult for new hires to create trusting connections with people they've never met in person or don't "run into" around the office. At the same time, some organizations - especially large ones - are finding that new levels of staff connection and communication are possible because of the shift to videoconference meetings. The ACLU's headquarters staff of 500 now connects for a weekly "Community Hour," an event that wasn't possible in the past because their facility didn't have a large enough space. 


\section{Empowered}

\section{Inclusive and equitable organizational cultures that embrace shared leadership}

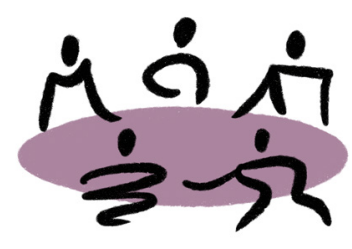

Cultivating inclusive organizational cultures and empowering staff to lead takes on new meaning when leaders prioritize equity and inclusion. Interviewees spoke of doing shared groundwork around what it means to be anti-racist, and holding space for staff to share their perspectives on how to center racial equity in their work - all with the intent to develop common language and a shared analysis of what it takes to advance equity and inclusion. ${ }^{8}$

Leaders expressed that centering equity and inclusion within their organizations is a critical first step to elevating equity in external-facing work; embodying equity and inclusion internally is a prerequisite to advancing equity in the world. For instance, CalMatters leaders have been working to grow a more diverse, inclusive, and equitable organization to support their team

Embodying equity and inclusion internally is a prerequisite to advancing equity in the world. and better serve Californians. Their goal is to have a staff with $50 \%$ people of color in 2021 , on the way to the $65 \%$ level that reflects the population of California. Alongside ongoing staff engagement and training this is, in turn, helping CalMatters enrich the diversity of its editorial sources and coverage, and translate and distribute more of its content via ethnic media partners. Young Women's Freedom Center, which fights for equity in its work to decriminalize young people, is engaged in long-term and ongoing efforts to continue to challenge anti-Blackness in its organization.

Leaders also emphasized the importance of letting go and making space for others to lead, especially when it can be natural to want to tighten their hold during turbulent times. When one leader had to take an unplanned leave after contracting COVID-19, staff stepped up and things were fine - a reminder of how important it is to nurture leadership in others. At ECHOS, which experienced huge growth in its services, the executive director asked other staff to take on roles presenting and launching pilot programs, enabling them to gain new responsibilities and develop as leaders. 


\title{
6. Committed to self-renewal
}

\author{
Space created for rest and rejuvenation
}

The crises of 2020 are taking a toll on the resilience of individuals - the life spring of resilient nonprofits. Staff are grappling with loss and complexity in their personal lives as they care for children, fight COVID-19, face economic challenges, and mourn the loss of loved ones often from afar. There is fatigue and depression from too much screen time and isolation. The continued need

Individual staff members are experiencing different stressors and have different needs. to combat white supremacy and racism in this country is leading to exhaustion and distress, particularly among people of color. Many people are experiencing deep anxiety about financial security, health, and the stability of our country. Self-care is an issue, to put it mildly.

Leaders of resilient nonprofits are modeling self-care at the top and making space for their teams to talk about what they're feeling. At HOPE Services, Inc., the team is racing to serve the compounding needs of the homeless. At a recent staff meeting, the organization made space for staff to share experiences of trauma, and leaders are doing what they can to engage and stay connected to a staff that has doubled in size due to COVID-19 and an influx of federal funding. "It's a marathon. Take a breath. Take a mental break," Executive Director Brandee Menino tells her team. Other interviewees report leaning into their own meditation practice, and offering breathing and mindfulness training to staff.

There is a recognition, however, that individual staff members are experiencing different stressors and have different needs. Leaders are actively reaching out to understand their needs and learn how the organization can help - while being careful to not assume a one-size-fits-all solution. They're making custom-fit supports available, like flexible use of personal time off (PTO), flexible work hours, stipends for personal wellness and remote work equipment, and support groups at employees' requests for affinities such as Black staff, LGBTQ+ staff, and caregivers.

Yet even with the extra attention there are concerns about exhaustion and breakdown. As the Partnership for Public Service's President and CEO Max Stier put it, "It's the normal care and feeding plus plus. I worry about burnout."The potential for burnout is coming from both challenging personal circumstances and the monumental demand that nonprofits are responding to. For instance, the ACLU has filed over 400 legal actions since Trump's election in 2016, a factor of ten more legal actions than the organization would have normally filed in that time period. As one interviewee shared, "We're seeing staff leave the organization with no jobs, saying, 'I've hit a wall. I need a break.' It's a confluence of COVID-19, the anxiety of the election, and everything coming together in a really fraught moment."

As COVID-19 persists and the crises continue, a more intentional emphasis on renewal may be in order. Simply catching one's breath will not be enough to sustain, let alone grow, personal resilience. Positive psychologists Sean Achor and Michelle Geilan point out that there are negative effects to toughing it out for long periods of time. "The key to resilience," they assert, "is trying really hard, then stopping, recovering, and trying again." ${ }^{\prime \prime}$ Leaders may need to consider what it will take to invest in renewal - for themselves and their teams - so they can carry on and continue to fight for a better future. 


\section{Connected}

Supported by personal relationships, institutional links, and community networks

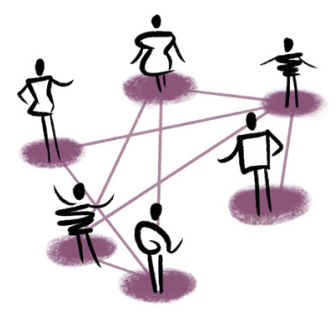

Nonprofits that are making it through the disruptions of 2020 are not doing it alone. They're connected to and in reciprocal relationships with individuals and groups beyond their organizations, including peers, advisors, allies, and communities.

Leaders emphasized the power of peer-to-peer contact - the ability to connect with others who are facing common challenges and can offer practical advice and a sense of community. President and CEO Pam lorio of Big Brothers Big Sisters of America emphasizes to affiliates across the country that they're not alone; they have a network of colleagues who are on a similar journey and can provide support and inspiration. "You have to be resilient when you see other people being resilient," Iorio said. "Resiliency is contagious." We heard stories of leaders participating in and

This has been a moment to forge and deepen institutional relationships across sectors and systems. holding space for connection with peers across a field. After COVID-19 hit, United Philanthropy Forum started weekly check-in calls where members could share what they were doing and learning.

Nonprofits are also aligning with organizations in allied and adjacent spaces. On-the-ground connections are proving to

be especially critical for service delivery and emergency response. The Houston-based team at ECHOS has been able to meet the surging demand for social services because people in their emergency response networks, developed after Hurricane Harvey, are now talking about COVID-19 and sharing strategies, tools, and resources. As Executive Director Cathy Moore said, "We're not big enough to know how to do everything. We do our best when we're part of networks and learning from others."

These institutional connections are reciprocal. Leaders of the National Immigration Law Center (NILC) saw grassroots groups struggling to stay afloat and meet the basic needs of immigrant communities. NILC allocated flexible funds through $\$ 10,000$ grants to 25 of these community-based organizations across the country. This has also been a moment to forge and deepen institutional relationships across sectors and systems. In Hawai'i, where the economic downturn has been especially sharp given the near total loss of tourism revenue, creative public-private partnerships are emerging. For example, the Agriculture Response and Recovery Working Group connects a broad coalition of stakeholders to respond to food and job instability across the state.

Communities are rallying to support nonprofits in need. At the California Academy of Sciences, members are hanging on even as service delivery has been largely put on hold. For Oakland-based Dimensions Dance Theater, which empowers African-Americans through the transformative power of dance, community relationships have been the organization's lifeblood at a time when live performance is suspended. Supporters have pitched in by connecting this nonprofit with resources, like CARES Act funding and the technological know-how to shift to online classes. 


\section{How funders can contribute to nonprofit resilience}

Funders are responding and adapting, too. Last spring, soon after the COVID-19 crises began, nearly $\mathbf{8 0 0}$ foundations signed the Council on Foundation's pledge to operate in a more flexible and relational way. Donors have been digging deep to increase their support, with charitable giving in the first half of 2020 up $7.5 \% .^{10}$ Institutional philanthropies are loosening grant restrictions, offering more flexible funding, centering grantee relationships, ${ }^{11}$ and elevating equity in their grantmaking. ${ }^{12}$

Relational and trust-based giving is not new. The concept is well articulated by the Trust Based Philanthropy Project, an initiative to address inherent power imbalances between foundations and nonprofits, and is aligned with most definitions of "good grantmaking."13 Historically, however, this approach has been preached more than practiced. But COVID-19, the growing movement for equity, and ongoing turbulence have accelerated the trend. ${ }^{14}$ The nonprofit leaders we spoke with were heartened by the shift, calling out the importance of regular and open communication with funders and the fundamental need for flexible, multi-year funding in an era of tumult.

At the same time, critics are asking: Are funders doing enough, particularly when it comes to support for nonprofits led by and serving people of color? Janine Lee, President and CEO of the Southeastern Council of Foundations, has observed an increase in "public criticism and shaming of funders by nonprofit leaders and watchdog organizations during this time. It's something I haven't seen at this level during my time in philanthropy." For instance, at the urging of Blackled social change groups, the National Committee for Responsive Philanthropy (NCRP) did an analysis of community foundation giving to Black communities based on 2016-2018 data. NCRP found that only " $1 \%$ of grants are going to Black communities, despite their $15 \%$ share of the local population."15 The data is looking similarly disheartening for more recent giving. The Center for Civic Innovation reviewed funding data from the $\$ 25$ million Greater Atlanta COVID-19 Response and Relief Fund. Initial findings show that while $96 \%$ of grantees said their work included a focus on Black communities, the vast majority of the funds ( $\$ 18$ million) went to white-led organizations. ${ }^{16} \mathrm{It}$ appears that in meaningfully democratizing their giving, many funders still have a long way to go. 


\section{Be in open dialogue, sharing information in both directions}

The nonprofit leaders we interviewed expressed appreciation for being in open dialogue with their funders. Many noted that their funders have been proactively checking in more than usual, asking: What do you need? How can we help? What are you observing on the ground and in your field? These conversations are welcomed opportunities for regular dialogue about a rapidly changing situation in their fields and within their organizations. In some cases, these interactions have resulted in new opportunities. During a check-in between the United Philanthropy Forum and the Hewlett Foundation, the idea was hatched for the Forum to lift up and document learning from philanthropic serving organizations' responses to the pandemic, followed by funding for the project from Hewlett.

Open dialogue means a two-way conversation, with funders checking in to understand the current state of nonprofits and vice versa. Concerned about 2021 funding, nonprofit leaders we spoke with called on funders to share updates on their priorities and plans. Social service organizations are anticipating a loss of the recent influx of government dollars, while demand remains high. Many expect corporate donations to dip as the economy remains weak or volatile. And they are observing some foundations in the midst of "strategy reviews" - a black box of planning that could result in shifts in priorities and/or decreased funding levels in order to protect endowments. As one nonprofit leader put it, it would be helpful to have more transparency and "information on the inside baseball" as funders strategize for 2021 and beyond.

\section{Offer flexible, multi-year funding, and more of it}

How might a trusting, relational approach to philanthropy translate into grantmaking practice? Nonprofit leaders applauded funders' move toward more flexible funding, and asked for more of it, especially multi-year support. We heard mentions of grant restrictions loosened, program grants shifted to general operating support (GOS), and deep appreciation for the financial certainty made possible by multi-year funding commitments. For many, unrestricted longer-term funding is especially important right now when other funding streams, like contracts with public schools and membership dues, are uncertain. According to ACLU Development Director Mark Wier, "We're seeing a real trend among institutional funders leaning toward GOS. Funders are recognizing how destabilizing a large restricted gift can be for a nonprofit. It can produce big outcomes, but can also come at a cost for the organization by pulling away staff time and resources from other strategic priorities."

As nonprofits face unprecedented disruption, demand, and related stresses on staff, funders can offer some relief by making it easy to receive grants. Simplified reporting requirements, fast grant processing, and direct access to grant dollars have helped. Ford Foundation, for example, offered the ACLU an unrestricted, unsolicited gift. "There's a lot of trust built into that," said Mark Wier. "It's saying we want to invest. We don't want to make this harder for you. We understand that you know how to put this money to good use. We don't need to micromanage." 


\section{Tailored support for capacity building can help, but not at the expense of ample flexible funding}

While the value of generous, long-term, flexible funding is indisputable, the desirability of targeted capacity building is less straightforward. Our research indicates that capacity-building resources work best when coupled with core support.

Creative and promising efforts are underway to support personal and organizational resilience in intentional ways. In particular, there is growing funder interest in self-care supports like well-being stipends, leadership sabbaticals, and other means to recharge ${ }^{17}$, such as the Nellie Mae Foundation's "A Year of Rest" campaign that offers retreat opportunities for Black people working for change. The Resilience Initiative, a Rockefeller Philanthropy Advisors' project funded by the Packard Foundation, is another inventive approach to meeting the needs of grantees. Through this Initiative, more than 200 Packard Foundation grantees can tap into a menu of resilience offerings - popular interests to date are leadership coaching and expert counsel in human resources, finance, technology, scenario

\section{Holding trusting} relationships and being in open dialogue remain core to fundergrantee success. planning, and fundraising. Rightsizing the pace and dosage of the offerings has been key, so that nonprofits can grow resilience for the long term while tending to immediate disruptions. Interviewees called out a number of additional ways funders can help, including facilitating opportunities for nonprofits to share back-office costs and proactively helping grantees access future government relief funds.

It's notable that we did not hear any strong requests from nonprofits for specialized capacitybuilding support. The paramount need was access to more flexible funding. As one nonprofit leader put it, "I need to be able to confidently make payroll. I don't really need expertise. I don't really need capacity building. I just need money. This was the case pre-COVID-19 and it's even more the case in COVID-19. I need it without strings attached. And not just emergency funding."

Of course, there is no one-size-fits-all solution. It all comes back to holding trusting relationships and being in open dialogue.

\section{Confronting funding uncertainty for 2021 and beyond}

Nonprofits are viewing 2021 and 2022 with apprehension, concerned by possible loss of philanthropic, government, and corporate support - in tandem with continued loss of earned revenue. While giving was up for the first two quarters of 2020, fundraisers are worried about what might be next. ${ }^{18}$ During the 2008 recession, many nonprofits already had funding committed through the end of the year, then experienced a drop in 2009. Will nonprofits encounter a similar delayed shock in 2021? Things are even murkier for 2022. One leader commented that in talking to funders about 2022, they just don't know what to expect, adding another level of complexity for nonprofits considering organizational investments and trying to plan for upcoming years. 
Relatedly, fundraisers are asking themselves: Will disaster-giving fatigue soon set in? The Hawai'i Community Foundation (HCF) is concerned. HCF's Hawai'i Resilience Fund raised \$12 million in the first eight weeks of COVID-19's spread. Now, according to Christine Van Bergeijk, HCF's

What will it take for funders to hold onto practices and mindsets developed in 2020? senior vice president and chief impact officer, donations have "slowed from the initial surge but donors continue to look for specific projects and initiatives that matter most to them. Donor's wealth or their business has been impacted, or they may be supporting other kinds of organizations. It is up to us to help them see what a huge difference their funding has made."

Moreover, if there are changes in funders' priorities and giving is down in upcoming years, which nonprofits will win and which will lose? Sam Cobbs, CEO of Tipping Point Community, urged funders "to not get too enamored with current portfolios and think about equity (versus equality) if or when rebalancing is needed."

There have been many positive signs of funder behavior shifting toward more trust-based and flexible giving. However, as one nonprofit leader put it, "The big question is: Does all of this revert when things normalize again?" For funders, the question is: What will it take to hold onto practices and mindsets that center trusting relationships and equity? 


\section{Looking toward a better future}

The nonprofits we spoke with have been unevenly impacted by the disruptions of 2020. Some are cutting back to bare bones, regrouping, and preparing for when they can resume in-person operations. Others are stepping into new and unforeseen opportunities to deliver on their missions. All are adapting in creative ways and rising to meet the needs of the moment. For these organizations, navigating present turbulence and future uncertainty has meant leading with purpose, facing harsh reality head on, learning from the past and rehearsing the future in order to adapt with nimbleness, maintaining open lines of communication, cultivating inclusive and empowered teams, being intentional with support for staff well-being, and staying connected to peers, advisors, allies, and communities.

With the shift to virtual programming and remote work, funding losses and gains, and more shocks anticipated in 2021, the work of nonprofits is in the process of being restructured. It's hard to know what the sector will look like on the other side of the current maelstrom. But we can be sure it will be different. Nonprofits and funders alike have an opening to chart a path toward a more just and equitable future. To be certain, there will be more loss, anxiety, burnout, and disruption along the way. However, as our research highlighted, leaders and organizations driven by clear and compelling purpose can persevere through adversity.

It is difficult to look beyond the day-to-day when there are urgent needs to address and so much feels beyond the control of most nonprofits. At the same time, looking to the future, imagining a better tomorrow, and cultivating resilience for the long term may be of greatest importance for nonprofits and funders now. In the words of poet and activist Sonya Renee Taylor:

\footnotetext{
"We will not go back to normal. Normal never was.

Our pre-Corona existence was not normal other than we normalized greed, inequity, exhaustion, depletion, extraction....

We should not long to return, my friends.

We are being given the opportunity to stitch a new garment.

One that fits all of humanity and nature."
}

Resilient nonprofits, with funders at their side, can lead the way. 


\section{RESILIENCE IN 2020}

\section{Stories of nonprofit resilience in action}

In our original study of nonprofit resilience, Resilience at Work, we profiled a number of nonprofits and how they confronted and responded to a range of disruptions. For Resilience in 2020, we returned to six of these organizations to learn how they have been faring in this time of shared and systemic disruption. While their work and organizations have been unevenly impacted, all have been buoyed by their resilience. These organizations came into 2020 well equipped to weather more storms to come. They have responded and adapted in alignment with their missions and, along the way, continued to cultivate resilience for the future.

24 Dimensions Dance Theater

Connected to community

25 HOPE Services Hawai'i, Inc.

Leveraging networks and adapting quickly for disaster response

27 National Immigration Law Center

Swift adaptation guided by strategic clarity

$29 \quad$ NatureBridge

Preparing to reemerge stronger, with equity at the center

$31 \quad$ Partnership for Public Service

Ready to pursue unanticipated opportunity

33 United Philanthropy Forum

Reinvented for these times 


\section{Dimensions Dance Theater}

\section{Connected to community}

Year founded:
Budget (2020):
Number of employees (2020):
Geography served:
Nature of disruption:

Primary resilience characteristics: Purpose driven, agile, connected
1972

$\$ 305,000$

26

Oakland, California

Inability to hold in-person programs; loss of earned revenue

Founded nearly 50 years ago in Oakland, California, Dimensions Dance Theater showcases and empowers African-Americans through the transformative power of dance. Over generations, Dimensions has knit together a tight community of youth and artists. Starting a decade ago, however, it saw its close community begin to geographically disperse as housing costs skyrocketed and the city's funding for the arts decreased. Many families moved two hours away from the city but still commuted back so that youth could attend dance programs. Yet despite the hurdles of geographic dispersion and funding challenges, the organization's commitment to its community and to the healing power of the arts kept it going strong.

\section{A new set of challenges}

The COVID-19 pandemic has had a severe impact on the arts sector, leaving venues shuttered and organizations with no earned revenue. Dimensions Dance Theater has been no exception.

The organization prioritized staying connected to its community from the start. They checked in with community members weekly. Board and staff all pitched in to respond to the crisis, learning about available resources through the CARES Act, quickly figuring out videoconferencing so they could shift to online classes, and holding workshops and master classes that engaged several hundred people. Biweekly movement classes and caring for one another have kept this organization going.

\section{Looking to the future while confronting the past}

Meanwhile, increased national attention on systemic racism has highlighted the continual necessity for Dimensions - an organization of and for African-Americans - not only to survive but to adapt for the next generation. "For many of us people of color, it feels like what our ancestors went through with civil rights. You're seeing history being repeated," said Executive Director Deborah Vaughan. She acknowledged that many in the Black community are simply trying to heal and persevere and get through what's happening now. But the inability of the nation to face its past, acknowledge inequities, and have the difficult conversations has been discouraging. Said Vaughan: "I just hope that this is a time of reckoning not only to ask but to demand change. We can clearly see what's happening to the earth, economy, education, our children. We need to revamp."

While the future of arts organizations feels uncertain, Dimensions considers art more important than ever. Art brings healing. And it's a legacy that must endure. 


\section{HOPE Services Hawai'i, Inc.}

\section{Leveraging networks and adapting quickly for disaster response}

Year founded:

Budget (2020):

Number of employees (2020):

Geography served:

Nature of disruption:
1989 as the Care-a-Van Program through the Office of Social Ministry; nonprofit affiliate incorporation as HOPE Services Hawai'i, Inc. in 2010 \$11 million

119

Island of Hawai'i

Surge in demand for services; health and safety accommodations for shelters, facilities, and frontline service programs

Primary resilience characteristics: Agile, committed to self-renewal, connected

HOPE Services, which provides housing-focused homeless programs and services on the island of Hawai'i, is no stranger to crises. Responding to Hurricane Iselle in 2014 and then the lower Puna lava eruptions in 2018 taught the organization to embrace the power of collaboration and lean into innovation in order to address dire community needs. Both disasters strengthened HOPE's ability to coordinate with government agencies, nonprofit providers, private funders, and even corporate entities to quickly identify needs, provide services, and avoid unnecessary duplication and misinformation. HOPE is also an organization that seizes the opportunity to try something new. Approached with an opportunity to develop new micro-unit housing during the lava flows, it quickly leveraged its networks to construct the shelters in one day while positioning them for longer-term use.

\section{Strength in community networks}

When HOPE Services started considering the potential of a pandemic in February 2020, its previous experience with disasters helped the agency to prepare. Understanding the critical importance of health and safety measures, this team quickly developed internal protocols and secured personal protective equipment for staff and clients. Strong networks allowed them to work with local health providers to provide COVID-19 testing, partner with hotels to arrange emergency temporary shelter for high-risk families, coordinate with county government to manage additional micro-unit shelters, and advocate for flexible terms on existing government contracts. These strong connections with other local agencies helped HOPE Services make the quick adaptations necessary to address accelerating needs.

\section{Adapting to changing community needs}

While in some ways responding to the pandemic has felt similar to responding to past disasters, this response reaches an unprecedented scale. The agency had previously provided $\$ 1$ million of rental assistance per year to families and individuals experiencing homelessness. Yet the organization was now tasked with distributing an additional $\$ 2$ million to households impacted by the pandemic in the course of just a few months. They had to quickly hire frontline staff even if managers and the necessary evaluation and human resource personnel were not yet in place to support them. In addition, a state funding crisis looms large, leaving the organization to consider its current 105\% growth in budget against a potential financial cliff coming in December when state funds run dry. No stranger to constant adaptation, HOPE Services is reallocating resources to address this uncertainty, turning to federal funding and continuing to lean on flexible funding from private foundations. 


\section{Paying attention to internal needs}

As CEO Brandee Menino reflected: "We are all stressed out. Self-care is an issue but I try to set an example as a leader. In our staffing meeting, we talked about trauma. We know it's a marathon; you have to take a breath, take a mental break." In addition to paying attention to mental health, as a leader, Menino is also keeping communication lines open. She sends frequent memos with updates to all staff and has an open door policy whereby staff will text or email her. And what keeps her going? "Always trying to do right by the people we serve." While no one can see into the economic uncertainties of the future, it's clear that HOPE Service's continual adaptation, strong networks, and attention to self-renewal will provide a promising foundation for its future. 


\section{National Immigration Law Center}

\section{Swift adaptation guided by strategic clarity}

Year founded:

Budget (2020):

Number of employees (2020):

Geography served:

Nature of disruption:
1979

\$20 million

75

United States

Office shut down and shift to remote work; heightened need/opportunity to advance the rights of low-income immigrants

Primary resilience characteristics: Purpose driven, clear eyed, agile, committed to self-renewal, connected

The National Immigration Law Center (NILC) has been defending and advancing the rights of low-income immigrants and their loved ones since their founding in 1979. With the 2016 election of Donald Trump, the fight for immigrant rights intensified, driving considerable growth for the organization. In fall 2016, NILC had a Twitter following of less than 14,000 , and an annual budget of $\$ 5$ million. In fall 2020, NILC's Twitter following was nearly 89,000 and their annual budget for fiscal year 2021 was $\$ 20$ million.

When COVID-19 hit, challenges for immigrant communities were once again amplified and exacerbated. Immigrants' health and finances were disproportionately impacted, and at the same time, they continued to be cut off from basic public support. Many are ineligible for healthcare. Disproportionate numbers of immigrants were working in dangerous conditions as essential workers, and those who didn't have social security numbers were excluded from economic relief.

Guided by a new strategic framework that centers immigrants within the broader fight for racial and economic justice, NILC rapidly responded to the needs of the moment. They were able to pivot quickly and effectively due to their clear strategic priorities, a team with lived experience as immigrants motivated to do what it takes, thoughtful support for staff well-being, connection to allies nationwide and to the movement for immigrant rights, and funders who were trusting and flexible.

\section{A fast transition to remote work, with staff needs at the center}

In early March 2020, Los Angeles, where NILC is headquartered, announced a state of emergency due to the spread of COVID-19. Within two weeks, NILC developed business continuity plans and all staff, who are based across the country, shifted to remote work. While the transition was fast, it wasn't easy. As COO Adnan Bokhari recalled, "As an executive team, we had to be honest with ourselves that we had less capacity. Folks were working at home, many with kids and families to care for." Anticipating myriad needs, in the first week of the shut down all staff members were given a $\$ 500$ emergency allowance to purchase basic supplies, like extra groceries. The focus on staff wellbeing continued with subsequent changes that included unlimited time off and a new compensation framework that offers improved benefits and pay. A key principle in the support for staff was introducing increased flexibility whenever people were being asked to do more. 


\section{Purpose driven and agile}

In 2019, NILC finalized and adopted a new strategic framework positioning the nonprofit as a racial and economic organization with the work of movement and power building and narrative change at its core, in combination with the legal and policy expertise for which it has been known. The framework has helped NILC leadership move quickly, make decisions with strategic clarity, and communicate the rationale to staff. As Deputy Director Kamal Essaheb said, "A core part of resilience is giving folks clarity about where we are going and what we are doing.... Our investment in [the strategic framework] is really bearing fruit." For instance, the weekend after George Floyd's murder, the leadership team gathered to discuss NILC's response. In Essaheb's words, "We had a good level of clarity about where we could contribute. We were measured and strategic about where we could invest. For example, we saw there was a need for a strong statement of solidarity from immigrant rights groups with Black Lives Matter."

NILC's clear strategic direction has also helped the team remain agile in an uncertain and rapidly changing environment. They were able to make the hard decision to pull back from work that had become less strategically critical in order to take advantage of the opening to shift the narrative around the importance of low-income immigrants in this country - immigrants who are on the frontlines of the pandemic as essential workers but without basic security and rights. The team made an upfront investment from their flexible funds in the new narrative change effort last spring. It was a hard thing to do at such a dynamic and overwhelming moment, but NILC's strategic framework helped clarify the need to make the move.

Staff and leadership also embrace the organization's purpose because it is core to their own identities and lived experience as immigrants, and because they can see they're making a tangible difference in people's lives. For Adnan Bokhari, a first-generation immigrant, his personal and professional lives came together when he joined NILC. In his words, it's "what carried me through. Not just myself but an entire team so dedicated to the work."

\section{Connected to a movement}

For years, NILC has seen its work as contributing to a long-term vision and movement for immigrant justice. According to Executive Director Marielena Hincapie, "We're committed to not only winning in the courts and achieving progressive policies but also movement building. We're intentionally trying to strengthen the capacity and health of the broader ecosystem for immigrant justice." Last spring, NILC was able to act on this commitment when it used some unrestricted funds for regranting to smaller immigrant rights organizations struggling to stay afloat and meet pressing needs among their local immigrant communities. NILC gave $\$ 10,000$ emergency grants to 25 organizations spread across the country. One group in Tennessee was in a meeting talking about how they were going to bridge a $\$ 3,000$ shortfall in their food budget when NILC's email came in. The emergency grant allowed the group to both bridge that gap and provide support to the people in their neighborhood.

\section{The power of flexible funding and two-way communication}

Unrestricted and flexible funds made it possible for NILC to transition quickly to remote work, provide staff with needed supports, make programmatic pivots, and distribute funds to community-based organizations. As Adnan Bokhari said, "We were able to do this because of our funders who had already provided us flexible funding. We didn't have to worry too much about risk mitigation." NILC has funders who made restricted funding unrestricted, changed reporting guidelines, and were engaging in two-way communication, asking: How can we help more? 


\section{NatureBridge}

Preparing to reemerge stronger, with equity at the center

Year founded:

Budget (2020):

Number of employees (2020):

Geography served:

Nature of disruption:

Primary resilience characteristics: Purpose driven, clear eyed, agile
1971

$\$ 5$ million

40

California, Washington, and Virginia (with participants from 26 states and 10 countries)

Shelter-in-place, school closures, and suspension of overnight, in-person programming at all sites for at least 18 months

NatureBridge, an environmental education nonprofit that runs overnight programs in national parks, is well rehearsed in managing through floods, wildfires, and the myriad risks that come with kids' programming in nature.

As part of a recent planning and risk management effort, leadership looked at the unrestricted cash that would be needed to weather the next big wildfire or flood. Analysts figured that a worst-case scenario would be if NatureBridge's programs at their largest site, Yosemite, were offline for a year. With the organization's current cash reserves, the analysts believed, such a severe scenario would be the end of the organization. This was the "Armageddon scenario," according to CEO Phil Kilbridge. Yet the reality has been worse. NatureBridge's in-person environmental education programs have been shut down at all of their sites since March 2020. The earliest they are likely to offer larger scale overnight programs is in fall 2021, a full year and a half after the initial shutdown. Yet the organization remains solvent; they continue to engage kids in nature through new online programs, and they are looking toward reopening with inclusive in-person programs for kids who have the least access to nature.

\section{Clear eyed paired with empathy}

After the shutdown last March, NatureBridge leaders knew that they needed to preserve cash and stop spending wherever possible, while approaching tough decisions with empathy for their people and partners. Schools were starting to inquire about cancellation policies and NatureBridge wanted to get ahead of these inquiries, keeping their long-term relationships with those schools front of mind. Campuses tried to adjust and reschedule programs as the COVID-19 pandemic evolved, but the situation rapidly worsened. More and more schools were being impacted and NatureBridge realized that the unknowns were too great to be able to run programs. Its leaders made a proactive decision to cancel spring programming and refund schools to preserve cash and curb expenses. Next, they needed to understand how they could cut costs. Given that personnel made up $65 \%$ of the organization's expenses, staffing is where cuts needed to be made. All staff members were either laid off, furloughed, or had a salary reduction, resulting in a $40 \%$ reduction in costs. NatureBridge also had National Park Service fees waived and negotiated lease terminations, among other cost-cutting measures.

With relationships intact and costs controlled, the team turned their attention to fundraising, garnering the dollars they needed to stay afloat and plan their pivot. NatureBridge launched its first fundraising effort driven by board leadership and engagement. Within a month the organization raised over \$1 million, and tapped into nearly 400 first-time donors. 


\section{Agile, future-oriented, and aligned by purpose}

NatureBridge's programmatic adaptation has emerged over time - in response to the dynamic context of the pandemic and its impact on schools, and through exploring what's possible now for serving the kids at the heart of their mission. After making the decision to cancel the spring 2020 programs, the NatureBridge team stayed close to the ground, listening to schools, teachers, epidemiologists, and others who could shine a light on a murky and changing situation and doing their best to look ahead and anticipate. It eventually became clear that most schools wouldn't be opening anytime soon, and the prospects were worse for the residential programs at the core of NatureBridge's offerings. The upshot: Leaders made the necessary decision to cancel all in-person programs for the 2020-21 school year.

Now, with their primary programming in nature on hold, NatureBridge is maintaining mission delivery, retooling, and reorienting for the future. The organization is staying in touch with schools and kids through a new distance learning program that brings nature and climate change education to the virtual classroom. NatureBridge is also extending its reach through virtual campfire chats with thought leaders in outdoor education. As a result, the organization will likely engage learners from all 50 states this year, as well as allies and supporters from communities across the country and the globe. NatureBridge plans to maintain online program delivery once inperson programs resume by, for example, extending those programs through remote engagement before and after in-person sessions.

NatureBridge is also using this moment to set the foundation for how it wants to reemerge, maintaining the optimistic stance that the organization will make it through and be stronger than before. With COO Judy Lin's leadership, staff have been doing a lot of scenario planning. They're looking at gloom-and-doom scenarios as well as best-case scenarios and even considering what it would look like if they were starting again from scratch. According to Judy Lin, "It is giving us a little bit of a fresh start to look at what we do and how we do it."The crisis is helping the team think "bigger" than what's possible at a single campus and come up with organization-wide solutions. Moreover, she continued, the longer-term change management is easier in some ways because "there is a clearer goal" and "a catalyst accelerating the change." As a result, teams are working across campuses and functions in "a more urgent and purposeful way."

As NatureBridge looks toward how it wants to reemerge, an important element involves coming back as a more equitable entity. The organization had been working to elevate diversity, equity, and inclusion for staff and students prior to the pandemic and the uprising for Black lives; providing access to nature for kids who need it most and supporting a diverse staff will continue to be a focus. As Phil Kilbridge commented, "Surviving this moment for most organizations would be enough.... We are telling ourselves that if we make the right choices we can be an even better organization when we're back." 


\title{
Partnership for Public Service
}

\author{
Ready to pursue unanticipated opportunity
}

Year founded:
Budget (2020):
Number of employees (2020):
Geography served:
Nature of disruption:

Primary resilience characteristics:
2001

\$21.5 million

120

United States

Shelter-in-place and office closures accelerating virtual service delivery

The Partnership for Public Service is a nonpartisan nonprofit working to make the federal government more effective and efficient. As such, the organization is skilled at adaptation, tailoring its approach to meet the needs and working style of each new administration while staying true to mission. When COVID-19 erupted in spring 2020, the Partnership anticipated a 20\% drop in revenue based on an expectation that government agencies would decrease their investments in staff capacity building in order to prioritize direct service, negatively impacting the Partnership's fee-for-service revenue. The reality was very different. Instead of a contraction, the Partnership has been able to expand through the move to digital service delivery.

The Paycheck Protection Program (PPP), the Partnership's board, flexible funders, and a dedicated team facilitated a fast and effective near-term response to the crisis caused by the pandemic. In addition to gaining economic security from the PPP, the Partnership's board nearly tripled their personal giving. Moreover, funders were, in President and CEO Max Stier's words, "actively trying to help in every which way they could," in particular by offering much more flexibility around grant terms. Alongside these supports for stabilizing the organization's finances, the Partnership's team "stepped up in a big way," responding with both urgency and capability. The anticipated drop in revenue did not materialize, and instead the organization has been experiencing growth.

\section{An "opportunity to make lemonade"}

"It's a really profound opportunity to make lemonade," said Stier."I think we'll wind up a ton stronger because of it. I think there are real silver linings here." An important silver lining has been the shift to digital practices.

The move to online service delivery and remote work has helped the Partnership expand its reach and more efficiently convene and connect with its core audiences. Prior to the pandemic, the organization had been working to expand its services beyond District of Columbia-based federal agencies to the $85 \%$ of the federal workforce outside of D.C. With virtual programs, the Partnership has been able to reach the 5,000 executives that it currently trains and more easily expand to serve the federal workforce around the country. The reach of the Partnership's existing programs has also grown. In the past, its annual event celebrating recipients of the organization's "Service to America Medal" could accommodate about 600 in-person attendees. In 2020, over 150,000 people joined the online gala over the course of a week. The move to virtual has meant that the walls of the venue come down and viewership is no longer limited to a single point in time.

Plus, remote work and service delivery are less costly. In addition to reduced travel expenses, there is also the opportunity to decrease investment in office facilities. The Partnership's second largest expense is space, and its lease is up at the end of 2021. Leaders had started the office search process thinking they would increase the organization's footprint, and now the plan is to decrease it by at least a third. 


\section{A focus on caring connection with staff}

This moment of newfound opportunity is not without loss and struggle; caring for staff has been critical for the Partnership's resilience. The serendipitous connectivity of the office is gone and there are no accidental kitchen or hallway connections. At the same time, there have been 12 new hires since the move to remote work and these personnel face the extra challenge of cultivating fellowship at a distance. Some staff have also been experiencing hurt, anger, and the need to be in dialogue around continued cases of police brutality and hoped for reckoning with systemic racism. Taken together, the potential for isolation and a fractured organizational culture is high.

The Partnership's leaders have responded by prioritizing intentional connection with their teams. They're actively listening to staff needs and perspectives through surveys and conversations. Managers are doing a lot of individualized outreach, checking in and gathering for one-on-one, in-person, socially distanced meetings when possible. Max Stier asks managers to pass along names of staff members who are struggling, then he reaches out for a personal conversation. As Stier said, "It's the normal care and feeding plus plus."

Looking forward, the Partnership for Public Service plans on continuing all virtual programming through August 2021. However, what the future holds remains uncertain. Stier had been engaging the board in scenario planning, and expects to do a major strategy refresh on the backend of the pandemic that clarifies their approach to scaling and identifies what to hold onto from their 2020 pivot. 


\section{United Philanthropy Forum}

\section{Reinvented for these times}

Year founded:

Budget (2020):

Number of employees (2020):

Geography served:

Nature of disruption:
1998; relaunched as United Philanthropy Forum in 2017

\$3 million

10

United States

COVID-19 and the uprising for racial justice driving new needs and opportunities for the Forum and its members

Primary resilience characteristics: Purpose driven, agile, open, committed to self-renewal, connected

After coming back from the brink of dissolution, the United Philanthropy Forum relaunched in 2017 with the mandate to connect and strengthen philanthropy serving organizations (PSOs). Leading into the relaunch, the Forum engaged in a participatory planning effort, resulting in a vision of "a courageous philanthropic sector that catalyzes a just and equitable society." Advancing racial equity and enabling network connections are central to the Forum's approach to moving toward this vision.

As a result of this recent reinvention work, the Forum came into the pandemic with deep clarity of purpose, a web of connections, caring leadership, and a sustainable business model - all of which are helping the organization remain healthy and sustainable in these turbulent times. The Forum was ready to respond to immediate crises, adapt to changing context, and tap into opportunities to advance their mission and vision.

\section{A time for network connections}

Being connected and creating connections for others have been key to the Forum's ability to thrive in this time. The organization serves as the connector of nearly 90 PSOs (e.g., Grantmakers for Effective Organizations, ABFE, Funders Together to End Homelessness) that collectively represent more than 7,000 funders. This role has proved essential as the Forum's members look to connect and learn from one another. Immediately after the pandemic hit, the Forum began holding regular check-in calls with members. It was a space for members to share how they were responding, exchange practical advice around areas of shared concern (like how to hold virtual convenings), and tap into expertise.

After the murder of George Floyd, the check-in calls expanded to discussions of racial justice, resulting in a powerful PSO response. The Forum led the charge on developing a joint statement on centering racial equity in how philanthropy responded to the pandemic, signed by more than 60 PSOs. According to CEO Dave Biemesderfer, "Having all of the PSOs in the same network facilitated us responding collectively in ways we haven't before."

It's not surprising that, since COVID-19 took hold, the Forum has seen growth in its membership. Some PSOs that had been considering membership have joined, recognizing that this is a moment when they want to tap into the network's timely insights and connections. Many of the Forum's members are also seeing growth in their own membership for similar reasons. As Biemesderfer observed, it's a moment when "PSOs are showing their vital values to the sector." 


\section{Caring and open leadership}

A spirit of mutual support and openness have characterized leadership and team dynamics within the Forum. Forum leaders made support for staff a priority in the shift to remote work. They're providing a range of resources for staff that acknowledge "the stresses and strain of working from home," like a flexible PTO policy, a generous sick leave policy, and a monthly stipend for addressing the new expenses associated with remote work. They're also keeping lines of communication open - through anonymous internal surveys, attentive listening, and thoughtful communications. As Biemesderfer said, "People really appreciate this openness. I think we all are grateful to still be working and doing work we want to be doing, and we talk about this as a team."

The board has been similarly supportive and flexible. They have switched to shorter and more frequent remote meetings. In light of the dynamic context, the board has been graceful about last-minute changes and given Biemesderfer latitude to take advantage of new opportunities.

\section{Tapping into new opportunities for learning, adaptation, and impact}

2020 has ushered in new opportunities for the Forum, and with clarity of purpose, leadership has been able to pursue these opportunities while ensuring strategic alignment. In addition to the member-to-member learning that the Forum facilitates, they are documenting (with grant funding from the William and Flora Hewlett Foundation) how member PSOs are stepping up and responding to the needs of the moment. The Forum also has a new partnership with the Bill and Melinda Gates Foundation (BMGF) to manage a \$9.1 million fund for growing the nonprofit infrastructure in the historically marginalized communities most impacted by the pandemic through support for intermediaries granting COVID-19 funds. The Forum was ideally positioned to manage the fund given their diverse network of PSOs representing the intersection of geographies, identities, issues, and practice areas in philanthropy.

\section{A sustainable business model and flexible funders}

The Forum's recent reinvention work included revamping their business model, which has given them a strong financial footing during the economic downturn. They now have a diverse revenue mix, including a number of different funding partners, and membership dues that fortunately had mostly come in before COVID-19 arrived. Concurrently, some expense categories are lower with the shift to virtual program delivery and the near absence of travel expenses.

On the funder front, the Forum has benefited from the predictability of their multi-year grants, and from funders shifting their grants to the Forum from program to general operating support. Also, funders proactively checking in to ask "How's it going?" and "What are you seeing?" has been helpful and opened new doors. Both the grant to document PSO responses, and the new partnership around the BMGF fund, came out of check-in conversations with donors.

\section{Looking toward a nimble and bold future}

As the Forum looks toward the future, its leaders are trying to figure out how to plan amid uncertainty. Their nimbleness has been key to their ability to pivot and pursue new opportunities in recent months, and they want to hold onto this agility. At the same time, they see an opening for the Forum and its member PSOs to play a leadership role as a new normal takes hold. The pandemic and the uprising for racial justice pushed many philanthropies to adopt more flexible and nonprofit-centric practices that are central to the more "just and equitable society" that the Forum envisions. Now the question is: What will it take to ensure these practices are permanent? And, as Biemesderfer mused: "If we're really serious about change, is there a new role for PSOs to play?" 


\section{Acknowledgments}

We are thankful for the funding of the S. D. Bechtel, Jr. Foundation that made this report, as well as the original study, possible. We are deeply grateful to Barbara Kibbe and the Effectiveness team for their leadership and hands-on support for this project. Barbara's wisdom and passion inspired us from start to finish.

We have listed on the following page all who contributed their guidance and valuable experience to this report, including our dedicated steering committee members who generously guided this project since its inception, as well as the many leaders who kindly accepted our request to talk again, and shared the journeys they've been on in 2020 with candor and insight.

Thank you all. 


\section{STEERING COMMITTEE MEMBERS}

Marselle Alexander-Ozinskas, Senior Program Officer, S. D. Bechtel, Jr. Foundation Victoria Dunning, Program Officer, BUILD, Ford Foundation

Ashleigh Halverstadt, Senior Evaluation and Learning Officer, S. D. Bechtel, Jr. Foundation

Barbara Kibbe, Director, S. D. Bechtel, Jr. Foundation

Matthew La Rocque, Program Officer, S. D. Bechtel, Jr. Foundation

Janine Lee, President and CEO, Southeastern Council of Foundations

Bob Tobin, Senior Consultant, Williams Group

Jennifer Wei, Organizational Effectiveness Officer, Hewlett Foundation

\section{INTERVIEWEES}

David Biemesderfer, President and CEO, United Philanthropy Forum

Adnan Bokhari, COO, National Immigration Law Center

Ashley Boren, Executive Director, Sustainable Conservation

Sam Cobbs, CEO, Tipping Point

Kamal Essaheb, Deputy Director, National Immigration Law Center

Melissa Felder, Chief Revenue and Marketing Officer, California Academy of Sciences

Jacob Harold, Executive Vice President, Candid

Pam lorio, President and CEO, Big Brothers Big Sisters of America

Abi Karlin-Resnick, Executive Director, Health Connected

Philip Kilbridge, President and CEO, NatureBridge

Judy Lin, COO, NatureBridge

Brandee Menino, CEO, HOPE Services Hawai'i, Inc.

Cathy Moore, Executive Director, ECHOS

Paula Morris, Director, Resilience Initiative

Brandon Nicholson, Executive Director, The Hidden Genius Project

Jessica Nowlan, Executive Director, Young Women's Freedom Center

Marcia Parker, Publisher, CalMatters

Pamela Sergio, Director of HR and Administration, Sustainable Conservation

Max Stier, President and CEO, Partnership for Public Service

Chris Van Bergeijk, Senior Vice President and Chief Impact Officer, Hawai'i Community Foundation

Deborah Vaughan, Artistic Director, Dimensions Dance Theater

Mark Wier, Chief Development Officer, American Civil Liberties Union

This report was brought to life with the editorial and creative talent of the Williams Group team and the gifted editor Jenny Johnston. 


\section{Endnotes}

1 Our analysis is informed primarily by the recent 2020 interviews and the deep research conducted for the original study (90 interviews conducted in 2018 and 2019), as well as ongoing dialogue and research around how nonprofits and funders have been experiencing and responding to these times.

2 Arundhati Roy, "The Pandemic is a Portal," Financial Times, April 3, 2020.

3 While these disruptions have been wide-reaching, nonprofits have been experiencing them very differently, depending on their mission, delivery model, and business model. Among the organizations we interviewed, approximately half have been experiencing growth, a quarter are holding steady, and a quarter have contracted. In addition, we noted the following about how the organizations we interviewed are doing and their respective sectors, service delivery models, and revenue streams: Nonprofits doing essential service delivery have experienced growth in demand and funding (driven, in part, by time-limited government funding), and simultaneously developed "COVID-19 friendly" models of service delivery (e.g., health and social services, homeless prevention). Nonprofits working on particularly relevant issues of the day (e.g., civil liberties, immigrant rights, nonprofit news, Black youth development) have also experienced high growth, in some cases fueled by one-time pandemic and racial justice response donations. Organizations working outside of "essential services" and that have historically done their work through in-person interactions have faced considerable challenges in adapting their mission delivery during the shutdown (e.g., out-of-school learning, arts programs, museums). Nonprofits with significant fee-for-service revenue streams have struggled, especially if their services were previously delivered in-person (e.g., membership models). Organizations whose work was already happening in the largely digital sphere have adapted with more ease and have been well positioned to take advantage of growth opportunities (e.g., advocacy, infrastructure, nonprofit news organizations).

4 "Health of the U.S. Nonprofit Sector," Independent Sector, October 2020.

5 "Race to Lead Revisited: Obstacles and Opportunities in Addressing the Nonprofit Racial Leadership Gap." Building Movement Project, July 2020.

6 Cheryl Dorsey, Jeff Bradach, and Peter Kim, "Racial Equity and Philanthropy," The Bridgespan Group, May 2020.

7 David LaPiana, "A Fundamental Reordering of the Sector?" LaPiana Consulting, October 15, 2020.

8 Mary-Frances Winter's, "Equity and Inclusion: The Roots of Organizational Well-Being," (Stanford Social Innovation Review, October 14, 2020) argues that organizations must see a DEl as a continuous process of examination and change (vs. one off trainings), in order to cultivate equitable, inclusive, and healthy organizational cultures.

9 Shawn Achor and Michelle Geilan, "Resilience is about how you recharge, not how you endure," Resilience: HBR Emotional Intelligence Series, 2017.

10 Eden Stiffman, "Giving Was Up 7.5\% in the First Half of 2020, New Report Says," The Chronicle of Philanthropy,

October 6, 2020. The Center for Effective Philanthropy's report," Foundations Respond to Crisis" (November 2020), affirms this upward trend.

11 Over $85 \%$ of respondents to a Council on Foundations survey reported adopting flexible grantmaking practices for existing grantees. ("Shifting Practices, Sharing Power," Dalberg Advisors, Council on Foundations, Philanthropy California, September 2020).

12 In July, Candid reported that 2020 funding for racial equity to date ( $\$ 4.2$ billion) had surpassed total funding for the previous nine years combined (\$3.3 billion 2011-2019). (Anna Koob, “What does Candid's grants data say about funding for racial equity in the United States?" Candid, July 24, 2020).

13 See numerous reports. For example: "New Attitudes. Old Practices: The Provision of Multiyear General Operating Support, Center for Effective Philanthropy," October 2020; “Is Grantmaking Getting Smarter," Grantmakers for Effective Organizations, 2017.

14 "Foundations Respond to Crisis," Center for Effective Philanthropy, November 2020. 
15 "Black Funding Denied: Community Foundation Support for Black Communities," National Committee for Responsive Philanthropy, August 2020.

16 "COVID-19 Funding Analysis," Center for Civic Innovation, accessed November 2020.

17 Jessamyn Shams-Lau and Leah Wilberding, "How Funders Can Support Individual Well-Being," Stanford Social Innovation Review, May 20, 2020.

18 Emily Haynes, Eden Stiffman, and Michael Theis, "Fundraising in Uncertain Times," The Chronicle of Philanthropy, October 28, 2020. 


\section{A VISION FOR CALIFORNIA}

The S. D. Bechtel, Jr. Foundation envisions a productive, vibrant, and sustainable California that is a model of success and a source of innovation.

\section{DIANA SCEARCE}

Diana Scearce is an independent consultant who has dedicated her career to helping social changemakers increase effectiveness and impact, in the U.S. and around the world. Diana's consulting practice focuses on strategy, learning, and collaboration. Her prior positions include director of learning and evaluation at the Skoll Global Threats Fund, director of evaluation and learning at the David and Lucile Packard Foundation, and director at the Monitor Institute.

\section{JUNE WANG}

June Wang, of CHANGE/D Consulting, helps social sector organizations leverage data and experience to improve practices. As an experienced organizational leader, facilitator, and project manager, June currently serves on the board of Fresh Lifelines for Youth (FLY) and as the program director with Listen for Good. She was previously the organizational learning officer at the William and Flora Hewlett Foundation.

This work is licensed under the Creative Commons Attribution 4.0 International License. To view a copy of this license, visit http://creativecommons.org/licenses/by/4.0/

Recommended citation:

Scearce, Diana and Wang, June (2020), Resilience in 2020:

Field Research on How Nonprofits Are Faring Amid Crisis and Disruption. doi.org/10.15868/socialsector. 37790 